\title{
Comparison of the Efficiency of the Mills "AGO-2" and "Activator-2SL" at the Mechanical Activation of Titanium Powder
}

\author{
Vladimir A. Poluboyarova, \\ Oleg P. Solonenko ${ }^{\mathrm{b}}$, Alexander A. Zhdanok ${ }^{\mathrm{a}}$, \\ Anton E. Chesnokov ${ }^{\mathrm{b}}$ and Irina A. Pauli*c \\ ${ }^{a}$ Institute of Solid State Chemistry and Mechanochemistry SB RAS \\ 18 Kutateladze Str., Novosibirsk, 630128, Russia \\ ${ }^{b}$ Khristianovich Institute of Theoretical \\ and Applied Mechanics (SB RAS) \\ 4/1 Institutskaya Str., Novosibirsk, 630090, Russia \\ 'Siberian Transport University \\ 191 Dusi Koval'chuk Str., Novosibirsk, 630049, Russia
}

The comparison of the efficiency of the mills "AGO-2" and "Activator-2SL" at the mechanical activation of titanium powder PTOM-2 has been carried out. Based on the calculation of mills energy efficiency there has been shown that the introduction of comparable energy values into titanium powder using different mills leads to similar results as for the volume distribution of particles is concerned, but considerable differences in counting distribution are observed.

Keywords: planetary centrifugal mechanochemical activator, energy efficiency of activator, specific surface, titanium, volume and counting distribution of particles.

Citation: Poluboyarov V.A., Solonenko O.P., Zhdanok A.A., Chesnokov A.E., Pauli I.A. Comparison of the efficiency of the mills "AGO-2" and "Activator-2SL" at the mechanical activation of titanium powder, J. Sib. Fed. Univ. Eng. technol., 2017, 10(5), 646-656. DOI: 10.17516/1999-494X-2017-10-5-646-656.

(C) Siberian Federal University. All rights reserved

* Corresponding author E-mail address: sanych@solid.nsc.ru,ipauli@list.ru 


\title{
Сравнение эффективности мельниц «АГО-2»
}

и «Активатор-2SL»

при механической активации порошка титана

\author{
В.А. Полубояров ${ }^{\mathrm{a}}$ О.П. Солоненко \\ А.А. Жданок ${ }^{a}$, А.Е. Чесноков ${ }^{\tilde{\sigma}}$, И.А. Паули ${ }^{\text {в }}$ \\ ${ }^{a}$ Институт химии твердого тела и механохимии СО РАН \\ Россия, 630128, Новосибирск, ул. Кутателадзе, 18 \\ ${ }^{6}$ Институт теоретической и прикладной механики \\ им. С.А. Христиановича СО РАН \\ Россия, 630090, Новосибирск, ул. Институтская, 4/1 \\ ${ }^{8}$ Сибирский государственный университет путей сообщения \\ Россия, 630049, Новосибирск, ул. Дуси Ковальчук, 191
}

Проведено сравнение эффективности двух планетарных мельнии марок «АГО-2» и «Активатор-2SL» при механической обработке (активации) порошка титана марки ПТОМ-2. На основе расчета энергетической мощности мельнии показано, что введение сопоставимых значений энергии в порошок титана разными мельницами приводит $\kappa$ схожим результатам по объёмному распределению частии, но к отличающимся в счетном распределении частиц.

Ключевые слова: механохимический активатор центробежно-планетарного типа, энергетическая эффективность активатора, удельная поверхность, титан, объемное и счетное распределение частиц.

\section{Введение}

Часто для решения проблемы измельчения материала и получения наиболее пригодных по дисперсности порошков требуется исследовать различное механохимическое оборудование, условия и методы обработки материала. Механохимическая обработка является очень энергоемкой операцией, и даже небольшое увеличение ее эффективности может дать ощутимый экономический эффект. В работах [1-7] были рассмотрены различные подходы к решению проблемы оценки эффективности механохимических аппаратов (мельниц). Изложенный материал демонстрирует, что понятие «эффективность воздействия механохимических аппаратов на обрабатываемое вещество» можно трактовать по-разному, и в каждом конкретном случае оно приобретает качественно новый смысл. Отсюда и множественность предлагаемых критериев оценки эффективности.

В физике наиболее общим критерием сравнения эффективности механических аппаратов выступает коэффициент полезного действия (КПД), который определяется отношением полезной работы к затраченной на ее производство энергии. Если с энергией, затраченной на работу механохимического активатора, все ясно, то с определением величины полезной работы существуют затруднения, так как эта величина зависит от поставленной задачи. Например, в задаче измельчения полезной работой является энергия, затраченная на образование новой поверхности, величина которой, согласно литературным данным, не превышает $10 \%$ от всей энергии,

$$
-647-
$$


накапливаемой твердым телом при механической обработке (МО). Аналогично, работа образования точечных дефектов не превышает 1 \% и т.д. Следовательно, точно выделить работу, затраченную на образование одного типа дефектов, не представляется возможным. Кроме того, ситуация, когда дефекты в твердом теле накапливаются монотонно, встречается крайне редко. Например, для многих оксидов МО приводит сначала к росту количества дефектов, а затем к его уменьшению. Следовательно, механическая энергия расходуется как на образование дефектов, так и на последующее их разрушение.

Допустим, что КПД механохимического активатора есть отношение энергии, введенной в вещество, к затраченной энергии. Тогда введенную в вещество энергию можно определить, например, по разности удельной теплоты растворения механически обработанного и исходного вещества [7].

Авторами [7] сделана оценка КПД центробежной планетарной мельницы ЭИ-2×150. В качестве тестового вещества использовался порошок ацетилсалициловой кислоты (АСК). На основании зависимости теплоты растворения АСК в воде от времени её МО авторы пришли к выводу, что с увеличением времени механической обработки АСК накапливаемая энергия не растет монотонно, а меняется периодически. Это явление можно объяснить сопутствующими релаксационными процессами: например, разрушением исходных межмолекулярных связей и следующей за этим релаксацией за счет образования других, что и приводит к изменениям величины накопленной в твердом теле энергии [7]. Максимальный избыточный (положительный) тепловой эффект растворения АСК был достигнут после 60 с МО исходного порошка при вводимой шарами энергии с мощностью 5 Вт/г и составлял 71 Дж/г, т.е. $24 \%$ энергии шаров вводилось в вещество. На поддержание же постоянной кинетической энергии шаров тратится мощность 800 Вт. Поэтому общий КПД не превышает 0,15 \%.

Оказалось, что такой же тепловой эффект растворения достигается при вводимой шарами энергии 300 Дж/г. Следовательно, можно ввести эту энергию за минимально короткое время, например за одну секунду, увеличив плотность материала шаров и их количество таким образом, чтобы вводимая шарами мощность достигала величины 300 Вт/г. Введение такой дозы в течение одной секунды приводит к избыточному тепловому эффекту растворения АСК - 75 Дж/г, что соответствует величине введенной в вещество энергии $~ 25 \%$ от энергии шаров, при этом КПД мельницы достигает $9 \%$, что приблизительно в 60 раз превышает исходное значение.

Другими словами, оценить эффективность механохимического аппарата можно и классически - по КПД, но для этого необходимо, чтобы используемый для этой цели тестовый материал хорошо растворялся, а запасаемая в нём энергия хотя бы не уменьшалась при увеличении времени МО.

Приведенный пример увеличения КПД подтверждает актуальность проблемы сравнения эффективности механохимических активаторов.

Таким образом, задача оценки эффективности различных механохимических активаторов не может быть решена в общем случае. Очевидно, что универсального критерия оценки всех аппаратов не существует. Необходим набор критериев, из которых при решении каждой конкретной задачи можно выбрать один или несколько адекватно отражающих эффективность воздействия каждого из используемых активаторов. В данной работе была проведена срав- 
нительная оценка эффективности двух планетарно-центробежных мельниц марок «АГО-2» и «Активатор-2SL».

Цель работы - определение и выбор наиболее приемлемых критериев, которые могут отражать эффективность активаторов для одного конкретного случая (в данном случае - процесса механохимической обработки порошка титана).

Поставленная цель достигалась решением следующих задач:

1) расчет энергетической мощности планетарных мельниц «АГО-2» и «Активатор-2SL»;

2) исследование в процессе МО удельной поверхности, объемного и счетного распределения частиц по размерам;

3) сопоставление эффективности механической обработки порошкообразного титана с использованием мельниц двух моделей при равной вводимой энергии;

4) оценка на основании полученных данных эффективности активаторов.

\section{Методика эксперимента}

В работе использовался порошок титана марки ПТОМ-2. Удельную поверхность образцов определяли методом БЭТ по тепловой десорбции аргона с внутренним эталоном. Перед проведением измерений все образцы были прогреты в токе газов Ar и Не при температуpe $120^{\circ} \mathrm{C}$ в течение 0,5 ч. Определение гистограмм объемного и счетного распределений частиц проводилось на анализаторе размеров частиц (0,04-2000 мкм) LS 13320 (Beckman Coulter). Морфология частиц определялась с помощью электронного микроскопа Evo MA15 (Carl Zeiss).

Основные характеристики мельниц «АГО-2» и «Активатор-2SL».

Планетарная мельница «АГО-2» [8] имеет два барабана объемом 100 мл каждый. Внутренний радиус барабана 35 мм, масса загружаемых шаров 200 г для каждого барабана, ускорение мелющих тел $186 \mathrm{~g}$, масса загрузки обрабатываемого материала 10 г. Максимальная скорость вращения центральной оси 1090 об/мин, барабанов 2220 об/мин.

Планетарная мельница «Активатор-2SL» [9] имеет два барабана объемом 250 мл каждый с внутренним радиусом 42,5 мм, масса загружаемых шаров 160 г для каждого барабана, ускорение мелющих тел $117 \mathrm{~g}$, масса загрузки обрабатываемого материала 8 г. Максимальная скорость вращения центральной оси 1045 об/мин, барабанов 1550 об/мин.

В качестве мелющих тел в обеих мельницах использовались стальные шары диаметром 5 мм.

Максимальное ускорение мелющих тел рассчитывали по формуле

$$
a=\frac{V^{2}}{R}=\frac{(2 \pi R)^{2}}{t^{2} R}=4 \pi^{2} n^{2} R
$$

где $R$ - внутренний радиус барабанов; $n$ - количество оборотов в секунду.

Энергетическая мощность мельниц рассчитывается по эмпирической формуле (2), полученной профессором В.А. Полубояровым,

$$
N=\frac{1}{12} \cdot \frac{m_{u}}{m_{n}} \cdot n^{3 / 2} \cdot R_{\sigma}^{3 / 2},
$$


где $m_{u}$ - масса шаров; $m_{n}$ - масса загружаемого порошка; $R_{6}$ - внутренний радиус барабанов; $n=a / g, a-$ ускорение шара, $g$ - ускорение свободного падения.

Вводимая в материал мелющими телами энергия

$$
E=N \cdot t
$$

\section{Результаты и обсуждение}

Предварительный анализ энергетической мощности мельниц в зависимости от времени механической обработки позволяет определить время воздействия на порошковые частицы при вводе в обрабатываемый материал равной величины энергии. Графики, представленные на рис. 1, построенные по результатам расчета, в соответствие с формулой (3), показывают, что вводимая энергия при механической обработке порошковых частиц в планетарной мельнице «АГО-2» примерно в 1,5 раза выше, чем вводимая энергия за тот же промежуток времени при механической обработке материала в планетарной мельнице «Активатор-2SL» при прочих равных условиях.

Для сопоставления результатов механической обработки частиц порошкового титана в планетарных мельницах «АГО-2» и «Активатор-2SL» в интервале времени от 15 до 120 с в соответствии с табл. 1 были получены образцы с режимами обработки порошковых частиц 1-3. Контрольный образец (режим 0) - образец без МО.

Исследованием дисперсного состава исходных порошковых частиц титана марки ПТОМ2 являются гистограммы объемного и счетного распределений частиц, представленные на рис. $2 a$ и 26 . Анализ гистограмм распределения частиц по размерам указывает на широкий диапазон - от 0,4 до 100 мкм, который включает в себя, как следует из гистограммы объемного распределения частиц, 10 \% частиц, размер которых не превышает 8,7 мкм $\left(d_{10}=8,7\right.$ мкм), и $10 \%$ частиц, размер которых более 47,26 мкм $\left(d_{90}=47,26\right.$ мкм), средний размер частиц со-

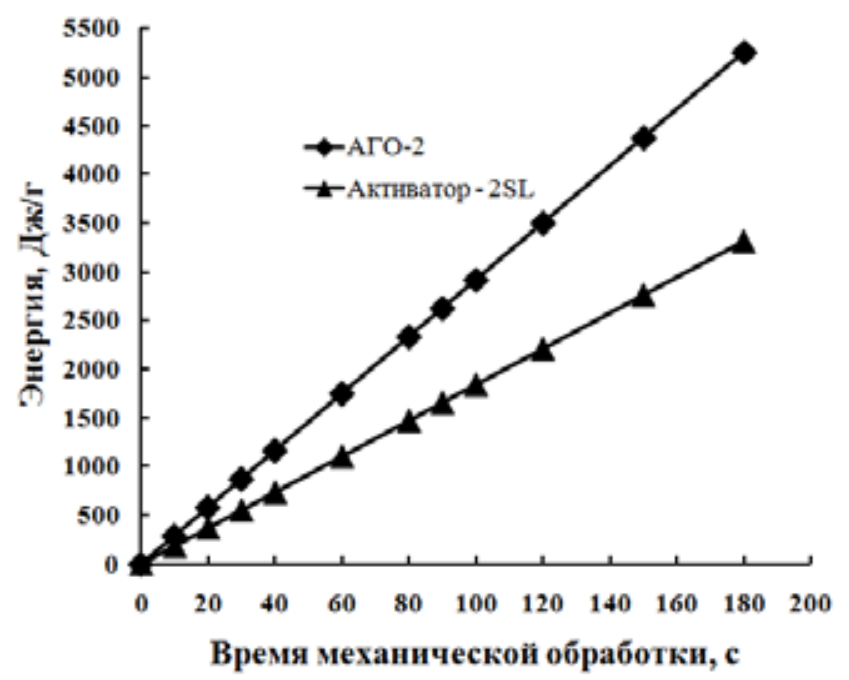

Рис. 1. Зависимость вводимой энергии от времени МО для планетарных мельниц «АГО-2» и «Активатор-2SL» 
Таблица 1. Характеристики частиц порошка титана в зависимости от времени механической обработки

\begin{tabular}{|c|c|c|c|c|c|c|}
\hline \multirow{2}{*}{$\begin{array}{c}\text { Режим МО } \\
\text { порошка }\end{array}$} & $\begin{array}{c}\text { Введённая } \\
\text { энергия, } \\
\text { Дж/г }\end{array}$ & $\begin{array}{c}\text { Время } \\
\text { обработки, }\end{array}$ & $\mathrm{S}_{\mathrm{yд}}, \mathrm{M}^{2} / \Gamma$ & $\begin{array}{c}\text { Введённая } \\
\text { энергия, } \\
\text { Дж/г }\end{array}$ & $\begin{array}{c}\text { Время } \\
\text { обработки, с }\end{array}$ & $\mathrm{S}_{\mathrm{yд}, ~} \mathrm{M}^{2} / \Gamma$ \\
\hline Режим 0 & 0 & 0 & 0,18 & 0 & 0 & 0,18 \\
\hline Режим 1 & 415 & 15 & 0,31 & 370 & 20 & 0,19 \\
\hline Режим 2 & 1106 & 40 & 0,26 & 1105 & 60 & 0,23 \\
\hline Режим 3 & 2108 & 80 & 0,15 & 2210 & 80 & 0,08 \\
\hline
\end{tabular}
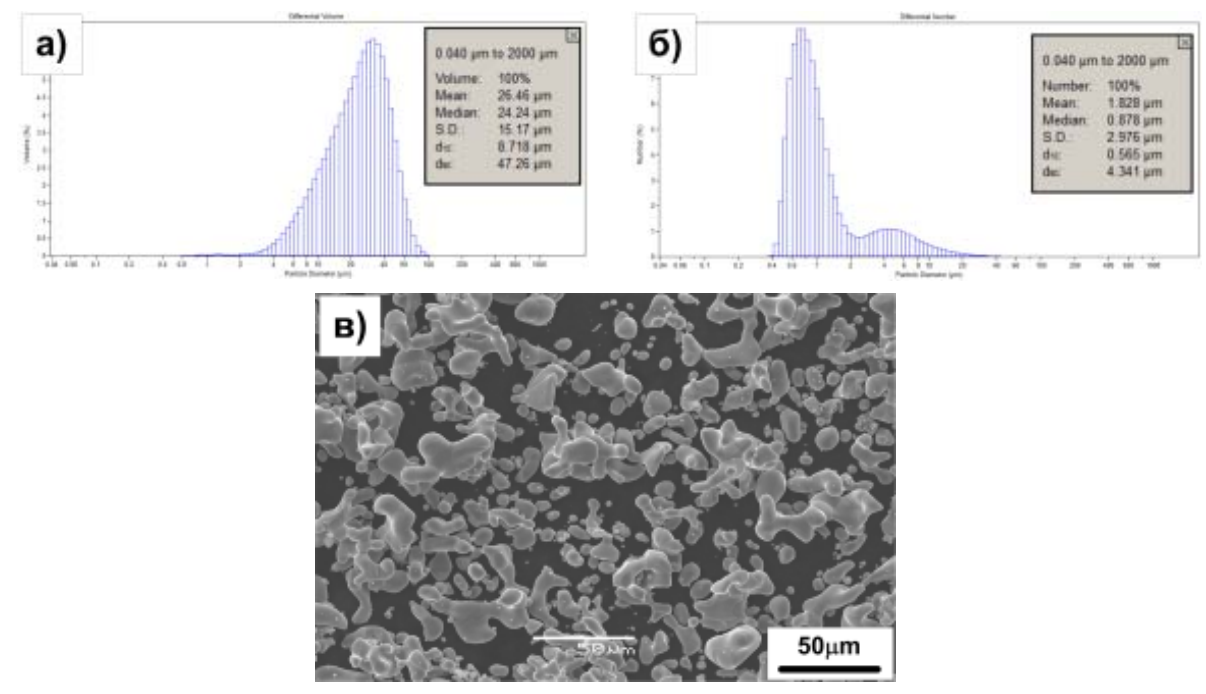

Рис. 2. Исходный порошок титана марки ПТОМ-2: $a$ - гистограмма объемного распределения частиц; $\sigma$ - гистограмма счетного распределение частиц; в - морфология частиц

ставляет 26,46 мкм. Из представленных результатов измерения на гистограмме счетного распределения частиц видно, что средний размер частиц равен 1,83 мкм, при этом значения $d_{10}$ составляет 0,57 мкм и $d_{90}-4,34$ мкм.

Морфология исходных порошковых частиц титана, изображенная на рис. 26 , визуально подтверждает наличие как крупных частиц (размером более 40 мкм), так и большого числа частиц с размером менее 2 мкм.

На рис. 3 представлены обобщенные результаты измерений, полученных при определении дисперсного состава образцов, включающие средний размер частиц и диапазон основной фракции в интервале $d_{10-} d_{90}$. В результате аналитической обработки гистограмм объемного распределения частиц по размерам (рис. $3 a$ ) можно утверждать, что поведение частиц во время МО отражает процесс агломерирования. Уменьшение диапазона основной фракции частиц в интервале размеров $d_{10-} d_{90}$ свидетельствует о появлении плотных частиц. Полученные соответствующие гистограммы счетного распределения частиц по размерам (рис. 3б) указывают на одновременное измельчение и формирование крупных 

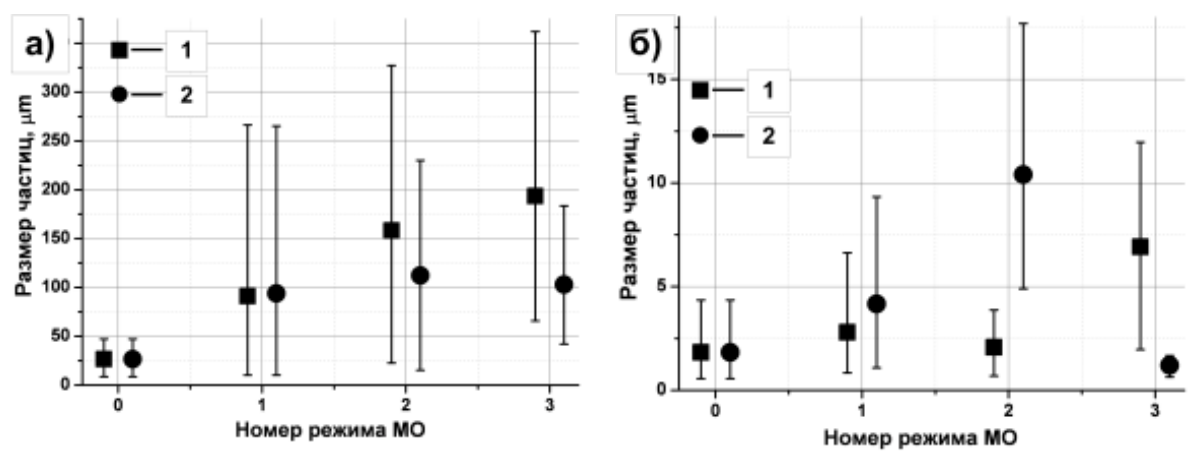

Рис. 3. Обобщенные результаты измерений размеров механически обработанных частиц: $a$ - размеры частиц, полученные в результате обработки гистограмм объемного распределения частиц по размерам; б - значения, полученные в результате обработки гистограмм счетного распределения частиц по размерам; 1 - MO в планетарной мельнице «АГО-2»; 2 - MO в планетарной мельнице «Активатор-2SL»

частиц. Процесс измельчения порошковых частиц сопровождается уменьшением размера среднего значения и одновременного уменьшения значений $d_{10}$ и $d_{90}$. Увеличение значений $d_{90}$ указывает на зарождение и рост новых агломератов. Необходимо отметить, что счетное содержание частиц, размер которых больше 5 мкм, не более 10 \% для всех измеряемых образцов.

При вводе в механически обрабатываемый материал сопоставимых значений энергии (табл. 1, режим 1) определенные объемные гистограммы распределения частиц по размерам являются идентичными. На рис. 4 представлены: 1) гистограммы объемного распределение частиц по размерам (рис. $4 a$ и б), имеющие бимодальную функцию распределения с максимальным значением размеров частиц в первой моде - 24 мкм для обеих мельниц. Максимальное значение размера частиц во второй моде равно 200 мкм для механически обработанного порошка титана в планетарной мельнице «АГО-2» и 250 мкм для механически обработанного порошка в планетарной мельнице «Активатор-2SL»; 2) гистограммы счетного распределения частиц по размерам указывают на равное количество частиц с размерами от 0,4 до 1,5 мкм при механической обработке порошковых частиц титана для обеих мельниц и на большее количество частиц с размерами от 1,5 до 4 мкм при механической обработке порошка в планетарной мельнице «Активатор-2SL» (рис. 4в и г), что указывает на различие значений удельных поверхностей механически обработанных порошков почти в два раза (табл. 1); 3) на СЭМ-снимках (рис. $4 \partial$ и е) представлена характерная морфология частиц для обеих планетарных мельниц, включающая механически обработанные частицы, механически обработанные агломераты и гантелеобразные фрагменты исходных порошковых частиц.

Таким образом, вводимая энергия для механической обработки порошковых частиц титана в соответствии с рассчитанным режимом 1 (табл. 1) не достаточна, а качественный процесс механической деформации частиц одинаков для обеих мельниц.

Исследование контрольных образцов механически обработанного порошка титана в соответствии с расчетным режимом 2 (см. табл. 1) показывает как рост размеров частиц, так и увеличение их количества (см. рис. 3 и рис. 5). При этом следует отметить, что процесс МО 

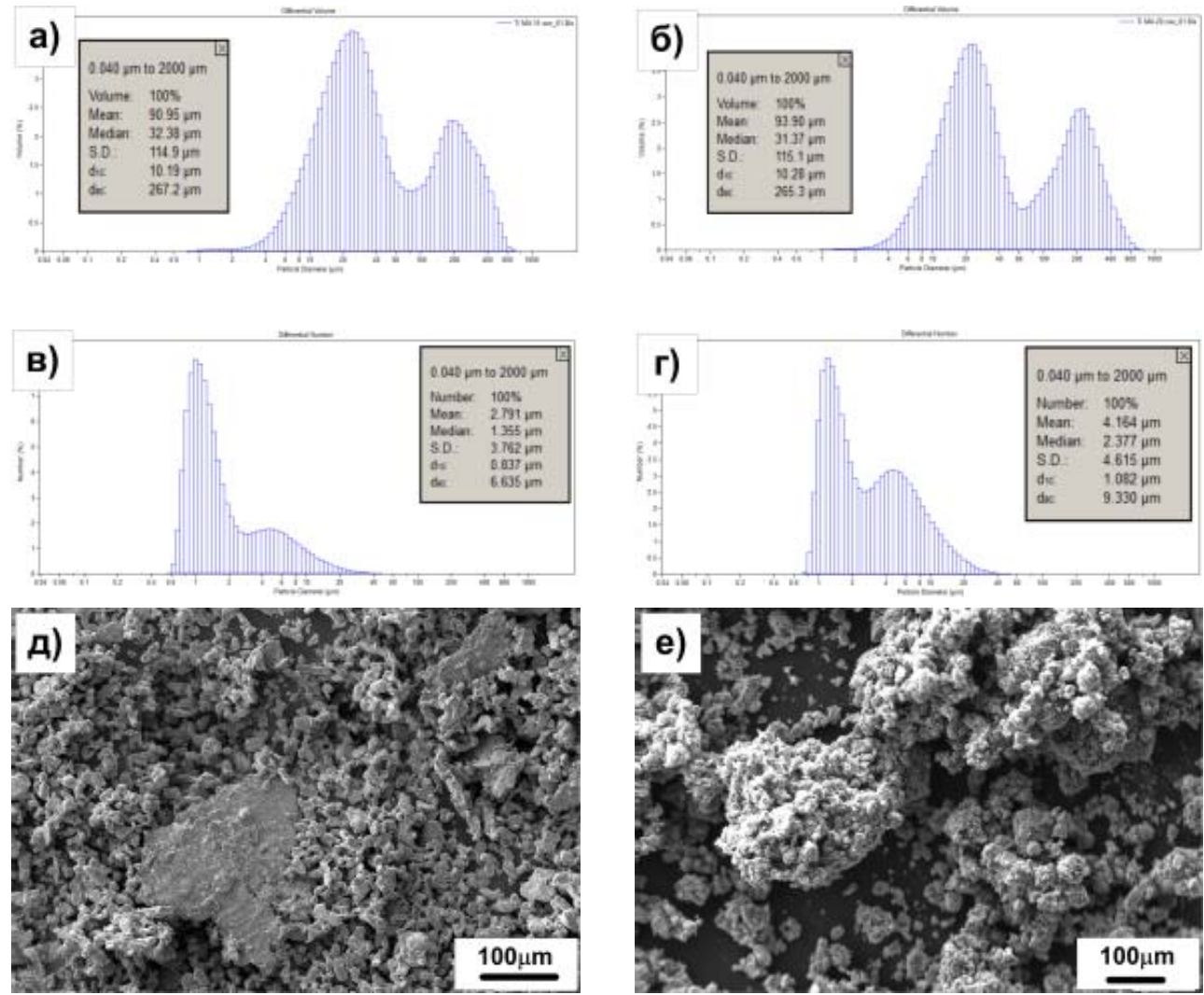

Рис. 4. Результаты обработки порошка титана ПТОМ-2. Мельница «АГО-2», время обработки 15 с, вводимая энергия 415 Дж/г: $a$ - объемное распределение частиц; в - счетное распределение частиц; $\partial$ - морфология частиц. Мельница «Активатор-2SL», время обработки 20 с, вводимая энергия 370 Дж/г: $\sigma$ - объемное распределение частиц; г - счетное распределение частиц; $e$ - морфология частиц

порошковых частиц в планетарной мельнице «АГО-2» сопровождается незначительным измельчением частиц с одновременно протекающей агрегацией частиц.

Увеличение введенной энергии (режим 3 , см. табл. 1) в процессе МО приводит к снижению значения удельной поверхности порошка титана (см. табл. 1) в результате механической деформации, приводящей к увеличению размеров и уплотнению частиц. Данная закономерность характерна для МО порошка титана в обеих планетарных мельницах.

Гистограммы объемного и счетного распределения частиц по размерам (рис. $5 a$ и в) подтверждают продолжение роста размеров агломератов и увеличение их количества в процессе МО порошковых частиц титана в планетарной мельнице «АГО-2».

Гистограммы исследований дисперсного состава МО порошковых частиц титана в планетарной мельнице «Активатор-2SL», представленные на рис. 56 и г, показывают, что режим, при котором получены данные частицы, является оптимальным режимом MO. При этом достигнуто максимальное измельчение частиц титана, средний размер которых составляет 1,2 мкм, а общее число агломерированных частиц с размерами более 1,671 мкм не превышает $10 \%$. 

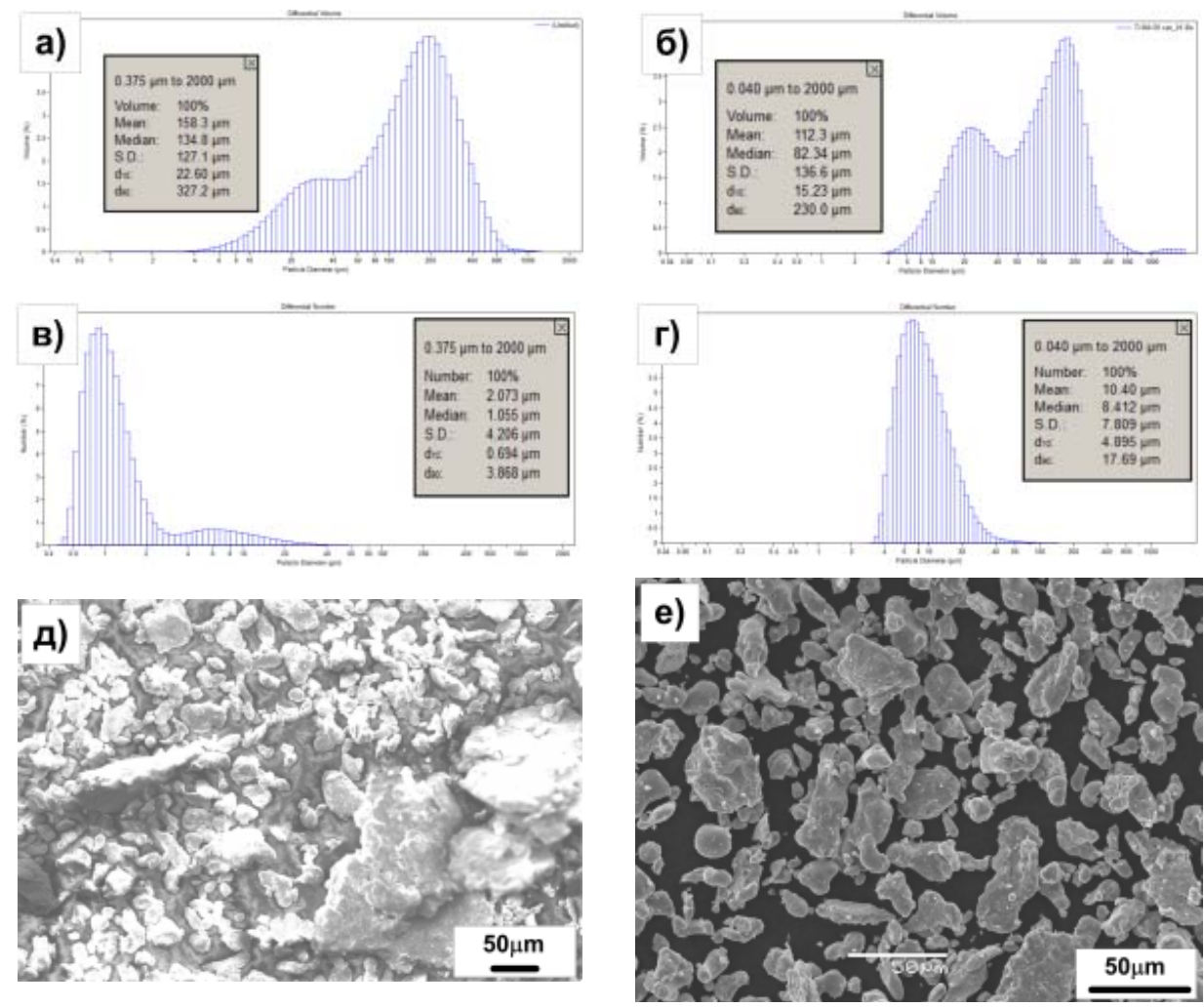

Рис. 5. Результаты обработки порошка титана ПТОМ-2. Мельница «АГО-2», время обработки 40 с, вводимая энергия 1106 Дж/г: $a$ - объемное распределение частиц; в - счетное распределение частиц; $\partial$ - морфология частиц. Мельница «Активатор-2SL», время обработки 60 с, вводимая энергия 1105 Дж/г: $\sigma$ - объемное распределение частиц; 2 - счетное распределение частиц; $e$ - морфология частиц

«Увеличение введенной энергии (режим 3, см. таблицу 1) в процессе МО приводит к снижению значения удельной поверхности порошка титана (рис. 6) в результате механической деформации, приводящей к увеличению размеров и уплотнению частиц. Данная закономерность характерна для МО порошка титана в обеих планетарных мельницах».

Таким образом, качественно процесс механической обработки у обеих мельниц идет одинаково - одновременно происходит измельчение и агрегация порошковых частиц титана. При этом интенсивность механической деформации частиц во время механической обработки порошка титана выше у планетарной мельницы «АГО-2», что объясняется большим количеством вводимой в вещество энергии в единицу времени.

\section{Выводы}

1. Энергетическая мощность планетарной мельницы «АГО-2» примерно в 1,5 раза выше, чем энергетическая мощность планетарной мельницы «Активатор-2SL» при прочих равных условиях.

2. Порошковые частицы титана характеризуются большим значением удельной поверхности, а также достигают максимальных её значений за меньшее время при механической обработке в планетарной мельнице «АГО-2». 

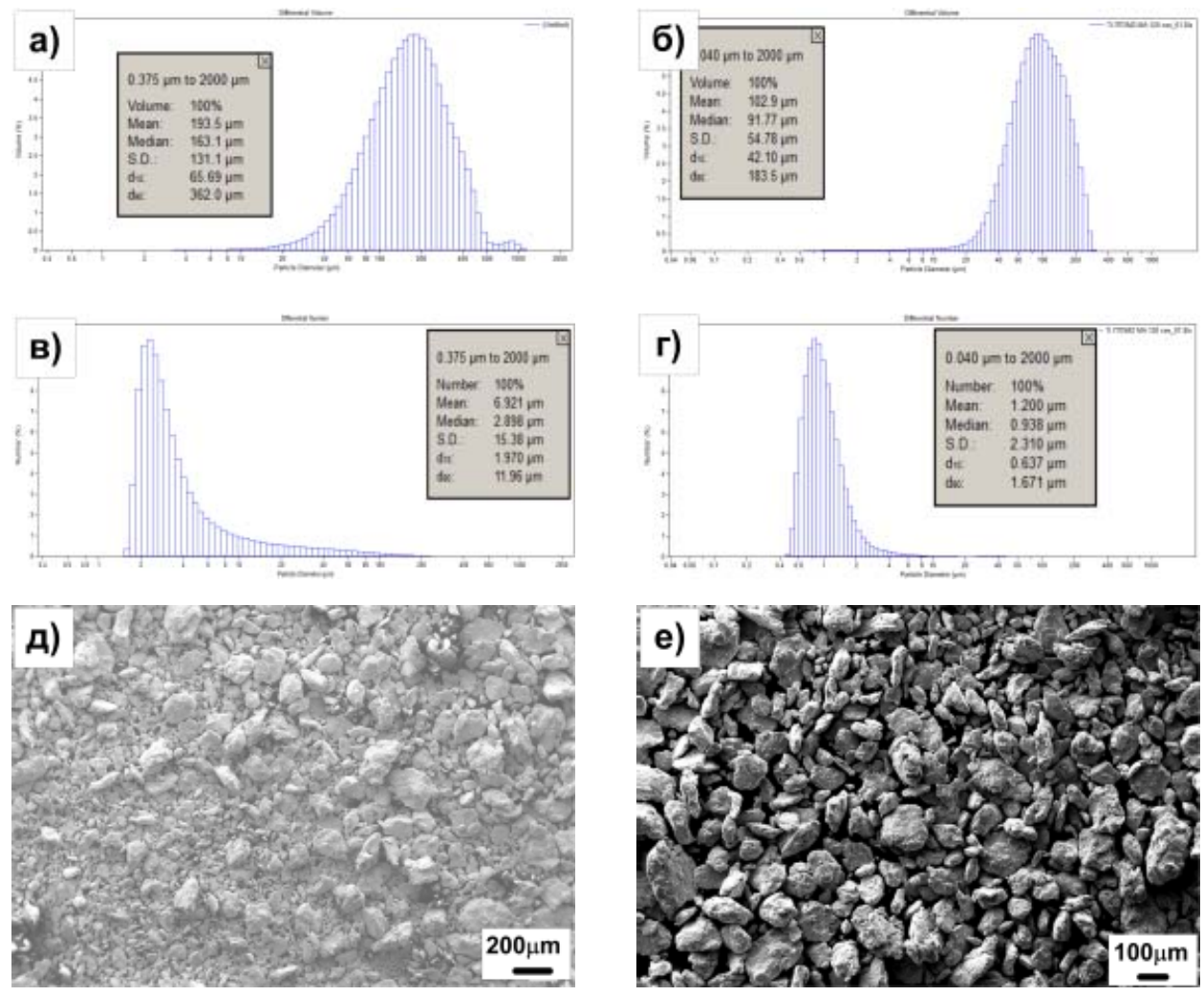

Рис. 6. Результаты обработки порошка титана ПТОМ-2. Мельница «АГО-2», время обработки 80 с, вводимая энергия 2108 Дж/г: $a$ - объемное распределение частиц; $в$-счетное распределение частиц; $\partial$ - морфология частиц. Мельница «Активатор-2SL», время обработки 120 с, вводимая энергия 2210 Дж/г: $\sigma$ - объемное распределение частиц; 2 - счетное распределение частиц; $e$ - морфология частиц

3. Сопоставимые значения введённой энергии в порошок титана разными планетарными мельницами, приводящие к схожим результатам по объёмному распределению частиц, имеют существенные отличия в счетном распределении частиц и, соответственно, в величине удельной поверхности.

Работа выполнена при поддержке Президиума СО РАН в рамках Междисциплинарного интеграционного проекта СО РАН № 2 на 2012-2014 z2.

\section{Список литературы}

[1] Болдырев В.В., Аввакумов Е.Г., Логвиненко А.Т., Савинкина М.А., Юсупов Т.С. Эффективность измельчительных аппаратов для активирования твердых тел. Обогащение полезных ископаемых: Сборник научных трудов. АН СССР. Сибирское отделение. Новосибирск: Институт горного дела, 1977, 5-13 [Boldyrev V.V., Avvakumov E.G., Logvinenko A.T., Savinkina M.A., Yusypov T.S. The efficiency of grinding devices for activation of solid bodies. Mineral processing: collection of scientific papers. Academy of Sciences of the USSR. Siberian branch. Novosibirsk: Institute of Mining, 1977, 5-13 (in Russian)]

$$
-655-
$$


[2] Бутягин П.Ю. Энергетические аспекты механохимии. Известия CO AH CCCP. Ceрия химические науки. 1987, 5, № 17, 48-59 [Butyagin P.Y. Energy aspects of mechanochemistry. Siberian branch of Academy of Sciences of the USSR Journal. Chemistry series. 1987, 5, № 17, 48-59 (in Russian)]

[3] Болдырев В.В., Павлов, С.В., Полубояров В.А., Душкин А.В. К вопросу об оценке эффективности действия различных машин в качестве механических активаторов. Неорганические материальь, 1995, Т. 31, № 9, 1128-1138 [Boldyrev V.V., Pavlov S.V., Poluboyarov V.A., Dushkin A.V. Revisiting the questing of the estimation of efficiency of various devices as mechanical activators. Inorganic materials, 1995, Vol. 31, № 9, 1128-1138 (in Russian)]

[4] Goldberg E.L., Pavlov S.V. A model of mechanical activation. Proc. of the 1st International Conference on Mechanochemistry. Kosice, 1993. Vol. 1. 66-70

[5] Павлов С.В. Кинетическая модель глубоких стадий механической активации: Автореф. дисс. канд. хим. наук, Сиб. отд-ние РАН. ИХТТИМС. Новосибирск, 1993 [Pavlov S.V. Kinetic model of deep stages of mechanical activation: candidate's of chemical sciences abstract of a thesis, SB RAS. Institute of Solid State Chemistry and Mechanochemistry. Novosibirsk, 1993(in Russian)]

[6] Полубояров В.А., Паули И.А.. Оценка эффективности химических реакторов для механической активации твердофазных взаимодействий. Сообщение 3. Химия в интересах устойчивого развития. 1996. Вып. 4. 519-523 [Poluboyarov V.A., Pauli I.A. The estimation of efficiency of chemical reactors for mechanical activation of solidphase interactions. Message 3. Chemistry in favor of steady development. 1996. Edition 4. 519-523 (in Russian)]

[7] Полубояров В.А., Коротаева З.А., Кисилевич С.Н., Панкратьев Ю.Д., Сысоев В.Ф, Андрюшкова О.В., Влияние механической обработки аспирина на кинетику его растворение в воде. ЖФХ. 1999. Т. 73. № 7 [Poluboyarov V.A., Korotaeva Z.A., Kisilevich S.N., Pankratiev Yu.D., Syusoev V.F., Andryushkova O.V.. Influence of mechanical treatment of aspirin on the kinetics of its dissolution in water. Journal of Physical Chemistry. 1999. V. 73. N. 7. (in Russian)]

[8] Пат. 1584203 РФ, МКИ В 02C17/08. Планетарная мельница. Аввакумов Е.Г., Поткин A.P., Березняк В.М.; Опубл. 18.06.87 [Patent RF 1584203. Planetary mill. Avvakumov E.G., Potkin A.P., Bereznyak V.M.. Published in 18.06.87. (in Russian)]

[9] Патент на полезную модель № RU 33037 U1 от 11.03.2003. Планетарная шаровая мельница. Автор: Леуткин Аркадий Алексеевич. Патентообладатель: Закрытое акционерное общество «Активатор».Utility model patent N. RU 33037 U1 of 11.03.2003. Planetary ball mill. The author: Leutkin Arkadiy Alekseevich. Patent owner: Closed joint-stock company «Aktivator». (in Russian)] 